\title{
EVIDÊNCIAS DO MERCADO DE PRODUTOS DA PEQUENA PRODUÇÃO NA REGIÃO DA TRANSAMAZÔNICA E BR-163 NO ESTADO DO PARÁ
}

\author{
EVIDENCE OF SMALL FARMING PRODUCTS MARKET DEVELOPED IN THE \\ TRANSAMAZON AND BR - 163 REGION IN THE STATE OF PARÁ
}

\author{
Antônio Cordeiro de Santana ${ }^{1}$ \\ Ádina Lima de Santana ${ }^{2}$ \\ Sérgio Castro Gomes ${ }^{3}$ \\ Ádamo Lima de Santana ${ }^{4}$ \\ Ana Karlla Magalhães Nogueira ${ }^{5}$ \\ Cyntia Meireles de Oliveira ${ }^{6}$ \\ Marcos Antônio Souza dos Santos ${ }^{7}$
}

\section{RESUMO}

Analisa-se o comportamento atual e futuro dos mercados institucional e não institucional de produtos da pequena produção, desenvolvida em projetos de assentamento da reforma agrária da região da Transamazônica e da BR-163 no estado do Pará. Apresentam-se os subsistemas de uso da terra na Amazônia, as características dos sistemas de produção e as formas de inserção no mercado, evidenciando os fatores que limitam a expansão da agricultura familiar e as oportunidades para seguir uma trajetória de uma agricultura de baixo carbono no contexto do desenvolvimento regional. Os resultados mostram que a continuidade do sistema de produção atual tende para uma especialização da agricultura familiar em apenas quatro cadeias produtivas: cacau, mandioca, madeira e pecuária. Por outro lado, há excedente de oferta para um conjunto de produtos, que deve ser exportado para outros mercados nacionais e internacionais e um excesso de demanda para uma cesta de produtos da agricultura familiar, cujo equilíbrio pode ser conseguido com o ajuste e a efetivação da atual política de apoio à agricultura familiar.

Palavras-chave: Agricultura de baixo carbono, projetos de assentamento rurais, produção familiar, mercado institucional.

\footnotetext{
${ }^{1}$ Doutor em Economia Aplicada pela Universidade Federal de Viçosa(UFV). Professor Associado pela Universidade Federal Rural da Amazônia (UFRA). E-mail: acsantana@superig.com.br

${ }^{2}$ Doutoranda em Engenharia de Alimentos pela Universidade de Campinas (UNICAMP). E-mail: adina santana@hotmail.com.

3 Doutor em Economia Aplicada pela Universidade Federal de Viçosa (UFV). Professor Titular da Universidade da Amazônia (UNAMA). E-mail: scgomes03@uol.com.br

${ }^{4}$ Doutor em Engenharia Elétrica pela Universidade Federal do Pará (UFPA). Professor Adjunto III da Faculdade de Engenharia da Computação e de Telecomunicações da Universidade Federal do Pará (UFPA). E-mail: alwkynew@gmail.com

${ }^{5}$ Doutoranda do Núcleo de Altos Estudos Amazônicos da Universidade Federal do Pará (UFPA). Professora Assistente da Universidade Federal Rural da Amazônia (UFRA). E-mail: karlla.magalhaes@ufra.edu.br.

${ }^{6}$ Doutora em Ciências Agrárias pela Universidade Federal Rural da Amazônia (UFRA). Professora Adjunta da Universidade Federal Rural da Amazônia (UFRA). E-mail: cyntiamei@hotmail.com.

7 Doutorando em Ciência Animal pela Universidade do Pará (UFPA). Professor Assistente da Universidade Federal Rural da Amazônia (UFRA). E-mail: marcos.marituba@gmail.com.
} 


\begin{abstract}
This paper analyzes the currentand future behavior for institutional andnoninstitutional market sof small farming products, developed insettlement project sof agrarianreformfromTransBR-163 region in the State of Pará. The subsystems of land utilization in the Amazon are presented, along with the characteristics of production systems and possibilities for market insertion, highlighting factors that can limit the expansion of family farming and the opportunities to follow a path of low carbon agriculture towards the regional development. The results show that the continuity of the current production systems will lead to a specialization of family farming in just four supply chains: cocoa, cassava, wood and livestock. On the other hand, there is excess supply for a set of products, which should be exported to other national and international markets, and excess demand for a set of products from family farming, whose balance can be reached by adjusting and enforcing the current policy for supporting family farming.
\end{abstract}

Keywords: Low carbon agriculture, rural settlement projects, familiar production, institutional market

Classificação JEL:C51, D41, Q13.

\title{
1. INTRODUÇÃO
}

Um dos pontos de apoio ao desenvolvimento local a partir dos Projetos de Assentamento (PA) da Reforma Agrária é a inserção dos produtos no mercado, inicialmente, por meio do mercado institucional, que contribui para ampliar o excedente da produção comercializável de um conjunto de produtos agropecuários e florestais madeireiros e não madeireiros.

Contudo, os PA da Transamazônica e BR-163, no estado do Pará, especificamente dos polos produtivos de Altamira, Itaituba e Santarém, enfrentam condições adversas na produção e comercialização dos produtos no que tange a limitações de quantidade, qualidade e preços competitivos para manter a parcela no mercado de produtos alimentares, oriundos da pequena produção rural. Com efeito, o enfrentamento de tais condicionantes necessita de amplo conhecimento das forças de mercado para orientar a escolha dos sistemas de produção, o portfólio tecnológico e o planejamento das cadeias produtivas, com vistas a contribuir com a transição da agricultura de derruba e queima atualmente praticada para uma agricultura de baixo carbono e de maior inclusão social.

As principais questões a responder envolvem a identificação das barreiras que limitam a participação ampla dos produtos da pequena produção 
rural oriunda dos assentamentos no abastecimento dos mercados atacadistas e varejistas de supermercados na área de estudo, bem como dos produtos com potencial para atender à demanda local, mediante a substituição de importações. Além disso, identificar as condições necessárias e de suficiência que devem ser superadas em todos os elos das cadeias produtivas, de modo a fazer a inserção dos produtos no mercado e contribuir para o desenvolvimento local.

Para alcançar esses pontos, o trabalho realizou um amplo estudo de mercado nos municípios vinculados aos polos de Altamira, Itaituba e Santarém, contemplando os estabelecimentos atacadistas, varejistas de supermercados, feiras livres e do produtor, agroindústrias, intermediários da comercialização (atravessadores) e as instituições reguladoras e parceiras que apoiam e/ou regulam os programas de fomento para produção e adquirem produtos para 0 mercado institucional. Os resultados deste trabalho de campo foram utilizados para calibrar os modelos de projeção da oferta e demanda dos principais produtos da pequena produção.

Os fundamentos teóricos utilizados no trabalho contemplam os mecanismos de regulação (desregulação) dos programas atrelados ao mercado institucional e as forças de oferta, demanda e comercialização que definem a dinâmica de mercado desses produtos.

O objetivo do trabalho foi analisar os limites e as oportunidades do mercado para os produtos agrícolas (milho, arroz, feijão, mandioca, cacau, café, pimenta-do-reino e espécies frutíferas); pecuários (aves, ovos, suínos, ovinos, caprinos, mel de abelhas e gado de corte e leite); peixe e florestais madeireiros e não madeireiros (andiroba, copaíba, castanha e seringa) da pequena produção rural com foco nos Projetos de Assentamentos dos polos de Altamira, Itaituba e Santarém no estado do Pará.

\section{FUNDAMENTAÇÃO TEÓRICA}

A economia rural da Amazônia se desenvolve em dois grandes sistemas de uso da terra: um sistema antropizado e outro sistema com floresta ou não antropizado, cujas trajetórias de desenvolvimento são impactadas pelas dinâmicas dos povoamentos urbanos e a logística de transporte e comercialização. Esses sistemas abrigam pelo menos quatro subsistemas de uso da terra e de manejo dos recursos naturais, cada um deles fornecendo matéria-prima para diversas cadeias, cujos produtos se destinam ao autoconsumo e aos mercados locais, nacional e internacional.

O sistema antropizado contempla dois subsistemas, cujos produtos têm valor de mercado: um orientado para o mercado restrito e outro para o mercado amplo. O subsistema que participa de mercado restrito tem como eixo principal a pequena produção, que pode ser enquadrada como agricultura familiar, 
definida na Lei $n^{\circ} 11.326 / 2006$ e ancorada nestas características: área do estabelecimento de no máximo quatro módulos fiscais; utilize predominantemente mão de obra familiar no estabelecimento; tenha renda familiar predominantemente originada no estabelecimento; direção do estabelecimento realizada pelos membros da família. Os estabelecimentos além de atomizados em dado território apresentam pequena escala de produção, limitada qualidade dos produtos e os canais de acesso ao mercado passam por atravessadores, agentes a serviço de agroindústrias e de mercados atacadistas e/ou varejistas, que determinam a formação dos preços.

No segundo subsistema, tem-se a produção que alimenta as principais cadeias de commodities, envolvendo as lavouras de altos insumos como grãos (soja, milho e arroz), dendê, frutas, plantios de eucalipto, pecuária de corte extensiva e extração de madeira. Na cadeia de grãos, a soja é o produto principal e destina-se ao mercado internacional. $O$ arroz e o milho fazem parte da rotação de culturas do sistema de produção da soja e são comercializados no mercado local (SANTANA, 2005; OLIVEIRA et al., 2013; COSTA et al., 2014).

O sistema com floresta ou sistema não antropizado contempla as cadeias de produtos florestais madeireiros e não madeireiros. Muitos desses produtos ainda não têm valor de mercado, o que dificulta a valoração e a determinação do retorno aos investimentos, bem como a comparação e/ou combinação das atividades dentro e entre os sistemas (SANTANA et al., 2012). Os produtos madeireiros são extraídos de planos de manejo comunitários das áreas de Projetos de Assentamento Agroextrativistas (PAE) nas Áreas de Reservas (AR), Unidades de Conservação (UC) e de Florestas Nacionais e Estatuais (FLONAS e FLOTAS). Esses produtos têm certificação de origem, cujo planejamento da atividade, fiscalização e comercialização são feitas pelas seguintes instituições: Instituto Chico Mendes de Conservação da Biodiversidade (ICMBio), Instituto Brasileiro do Meio Ambiente e dos Recursos Naturais Renováveis (IBAMA), Serviço Florestal Brasileiro (SFB), Secretaria de Meio Ambiente (SEMA) e Instituto de Desenvolvimento Florestal do Pará (IDEFLOR).

Nesses dois grandes sistemas de uso da terra, as cadeias produtivas são impactadas e governadas pelos povoamentos urbanos, a logística de transporte abrigam os mercados atacadistas e varejistas de supermercados, viabilizando a comercialização dos produtos. Esta relação configura a dinâmica de uso da terra na Amazônia. Este trabalho, com efeito, analisa o mercado de produtos oriundos deste sistema antropizado de uso da terra na Amazônia.

Um traço importante da produção desse subsistema é que os produtores não influenciam os preços de mercado, porque não compreendem como tais mercados funcionam. Os produtos integram as cadeias produtivas de grãos, farinha, frutas, cacau, pimenta - do - reino, café, hortaliças, carne (boi, porco, 
criação, galinha), leite, ovos e peixe (SANTANA, 2012). Ressalta-se que nenhuma dessas cadeias está estruturada na Amazônia, uma vez que os elementos dos elos da cadeia atuam de forma isolada (SANTANA, 1998; SANTANA, 2002; SANTANA et al., 2008).

$\mathrm{Na}$ área da pesquisa, com exceção da pecuária de corte extensiva, toda a produção agrícola se enquadra como agricultura familiar, em específico, a realizada nos projetos de assentamento da reforma agrária, conforme dados do Instituto Brasileiro de Geografia e Estatística (IBGE, 2008). Os agricultores não conhecem o comportamento do mercado, são tomadores de preços $\mathrm{e}$ participam de mercados restritos com a produção, a qual é entregue para atravessadores, comerciantes dos mercados municipais, feiras livres e uma pequena parcela vai para o mercado institucional.

Assim, o vínculo dessa produção com o mercado é restrito, em função da escala e qualidade do produto, preços competitivos, agregação de valor e formas de negociação por contratos (SANTANA, 2013). A produção opera na franja competitiva do mercado e sua inserção ao mercado amplo exige mudanças estruturais para viabilizar a formação de laços de confiança e solidariedade no processo de organização dos produtores, operando os ativos coletivos de armazenamento e agroindustrialização; e efetivando a venda de produtos e compra de insumos.

Atualmente, o principal canal de comercialização é conduzido pelo atravessador, o qual faz a conexão entre a produção e os mercados urbanos atacadistas e varejistas. $\mathrm{O}$ atravessador, dado o pequeno excedente produzido nos estabelecimentos, reúne certa quantidade de uma cesta de produtos de maior valor comercial para otimizar o transporte e atender aos contratos (encomendas) do mercado urbano (SANTANA, 2013). A cesta de produtos, em geral, contempla farinha, cacau, peixe, queijo, animais, frutas e hortaliças. Essa produção não tem certificação e alguns deles não atendem à legislação comercial, portanto, são comercializados de forma clandestina.

Nesse caso, o mercado institucional, mediante ação do Programa de Aquisição de Alimentos (PAA) e do Programa Nacional de Alimentação Escolar (PNAE), constitui uma âncora de sustentação da renda dos estabelecimentos que compõem esse subsistema por reduzir risco e ampliar as expectativas dos produtores para incrementarem a produção que alimenta as cadeias mais rentáveis. Esse é um passo fundamental para que os produtos da pequena produção rural dos projetos de assentamentos da área de estudo evoluam do mercado restrito e conquistem uma parcela significativa do mercado amplo.

A estrutura de mercado para estes produtos opera próximo da concorrência pura, cuja principal característica é a atomização dos produtores, cada um produzindo uma parcela insignificante do produto ofertado no mercado e atuando como tomador de preço do atravessador e/ou dos agentes intermediários da comercialização a serviço dos mercados urbanos atacadistas 
e varejistas (SANTANA, 2012; NOGUEIRA et al., 2013; SANTANA et al., 2014). A predominância das transações ocorre no mercado spot que é um mercado instantâneo em que os pagamentos são realizados à vista com a entrega imediata dos produtos. Essas transações são comuns com os atravessadores e direto com os consumidores ou com feirantes, sendo o pagamento à vista $\mathrm{e}$ entrega imediata do produto. As negociações a prazo ocorrem com o mercado institucional para venda de animais a serem abatidos, entrega de leite a laticínios, frutas a agroindústrias, cacau por agentes a serviço de empresas internacionais, venda de madeira às serrarias e venda de peixe aos frigoríficos. Em quaisquer das situações os produtores aceitam os preços determinados pelo mercado.

O mercado institucional pode contribuir para atenuar a instabilidade da renda dos produtores, uma vez que o alcance da política tem pequena participação no valor da produção dos principais produtos demandados. Entretanto, levando-se em conta o conjunto das políticas, pode-se contrabalançar diversas forças causadoras da instabilidade da renda. Assim, a organização da produção, o aumento na escala de produção, a melhoria na qualidade dos produtos e a agregação de valor tornam mais elásticos em relação ao preço e à renda, de modo que ficam menos sensíveis aos efeitos da concorrência e das condições adversas do clima (SANTANA et al., 2011). A adequação da oferta à demanda pode aproveitar o efeito do crescimento da população dos espaços urbanos e do aumento dos gastos em alimentos. Isso é proporcionado pelo aumento da renda per capita que é incrementada com as políticas de transferência de renda, assim como pelo aumento da competitividade da produção local frente aos produtos importados.

No elo da produção, justifica-se a ajuda pública para compensar os termos de troca desvantajosos das negociações com os oligopólios que vendem insumos e que compram os produtos da agricultura familiar (SANTANA, 2013). A paridade diz que, ao longo dos anos, um produtor é capaz de adquirir uma quantidade total de insumos e serviços para uma dada quantidade produzida dos produtos agrícolas. Essa quantidade de produção real deve sempre gerar a mesma renda real. Isso significa que a razão de paridade entre os preços recebidos e os preços pagos pelos produtores deve permanecer constante ao longo do tempo, no caso de uma paridade completa. Nessa direção, caminham os programas PAA e PNAE que adquirem os produtos da agricultura familiar a um preço superior ao praticado nos mercados locais.

O elo do comércio varejista de feiras livres é um dos principais pontos de apoio ao desenvolvimento sustentável da agricultura familiar e, geralmente, não é contemplado nas políticas públicas (SANTANA, 2013). A feira livre, além de ser um espaço para as negociações dos produtos é um espaço social e cultural, em que os produtores e comerciantes atualizam suas informações familiares e de negócios, trocam ideias, tomam decisão e participam de 
eventos lúdicos com os membros da família. Além disso, dispõe de informação sobre os diversos nichos de mercado que consomem os produtos da agricultura familiar e que não são apropriadas pelos produtores com vistas a orientar e qualificar a produção.

Por fim, a pesquisa de mercado busca gerar e qualificar as informações sobre os mercados de produtos agrícolas, pecuários, pesqueiros, madeireiros e não madeireiros, com foco na identificação daqueles produzidos em projetos de assentamentos da reforma agrária, com vistas a orientar o planejamento da produção e a articulação com as políticas públicas de apoio ao desenvolvimento de uma agricultura de baixo carbono e integrada aos demais elos das cadeias produtivas.

\section{METODOLOGIA}

A área de estudo contemplou os municípios dos polos de Altamira (Anapu, Pacajá, Senador José Porfírio, Porto de Moz, Vitória do Xingu, Altamira, Brasil Novo, Medicilândia, Uruará e Placas), Itaituba (Rurópolis, Trairão, Itaituba e Aveiro) e Santarém (Belterra, Mojuí dos Campos e Santarém), por representarem os mercados onde são comercializados os produtos oriundos da agricultura familiar.

Os dados utilizados no trabalho são de fontes secundária e primária. As informações secundárias referem-se às variáveis quantidades (produzidas e consumidas) dos produtos identificados no mercado; preços dos produtos; produto interno bruto per capita e população disponíveis nas estatísticas do IBGE; salário rural e o Índice Geral de Preços disponibilidade interna da Fundação Getúlio Vargas (FGV); e precipitação pluviométrica de estações meteorológicas do Ministério da Agricultura, Pecuária e Abastecimento (MAPAPA) para os pólos comerciais da área de estudo (Altamira, Itaituba e Santarém), no período de 1999 a 2011. Essas séries históricas foram utilizadas na estimação de suas taxas de crescimento nesse período e das funções de oferta e demanda dos produtos, com vistas a determinar os coeficientes de elasticidades - preço, renda e cruzada. As taxas de crescimento e as elasticidades são os parâmetros que calibram o modelo de projeção da oferta e da demanda dos produtos.

Com efeito, os dados primários das unidades produtivas dos mercados atacadistas e varejistas foram obtidos nos meses de junho a agosto de 2013 por meio de pesquisa de campo. A maioria dos municípios não possui estabelecimento atacadista e/ou varejista. Alguns municípios, nem mesmo têm feiras livres ou mercados municipais e quando existem funciona apenas um dia na semana. As unidades de venda destes municípios são abastecidas por outros municípios da área de pesquisa e/ou por agentes intermediários. No total foram aplicados 111 questionários, sendo 46 no polo de Santarém, 40 no polo de Itaituba e 25 no polo de Altamira, cobrindo quase a totalidade dos estabelecimentos que comercializam produtos da pequena produção rural. 
As informações primárias e secundárias foram consolidadas nos seguintes pólos - chave: Altamira contempla os municípios de Altamira, Medicilândia, Uruará, Anapu, Brasil Novo, Porto de Moz, Vitória do Xingu, Pacajá, Placas e Senador José Porfírio; Itaituba integra os municípios de Itaituba, Trairão, Rurópolis e Aveiro; e Santarém representa os municípios de Santarém, Belterra e Mojuí dos Campos. O polo de Santarém é o grande mercado, que exerce importante relação comercial com os demais polos por meio das compras e vendas dos produtos agrícolas e não agrícolas. Por exemplo, Santarém demanda queijo e gado do polo de Itaituba, cacau do pólo de Altamira e vende frutas (abacaxi e melancia), arroz,ovos de galinha e frango de granja para os polos de Itaituba e Altamira.

Os resultados da pesquisa de campo foram utilizados para calibrar os modelos de projeção da demanda e da oferta de produtos da agricultura familiar para o agregado do mercado de cada polo.

\subsection{Modelo de Mercado}

O mercado dos produtos da área pesquisada foi definido pelas equações de oferta e demanda, à luz da teoria microeconômica sobre o mercado de concorrência pura, por ser a estrutura que mais se aproxima da realidade da produção, comercialização e consumo dos produtos da pequena produção rural local. O mercado de produtos opera com características próximas da concorrência pura pelas seguintes razões (SANTANA, 2005; SANTANA et al., 2011a,b; OLIVEIRA et al., 2013):

a) Grande número de produtores e de compradores, cada qual transaciona uma pequena parcela do volume total de produtos agropecuários e florestais madeireiros e não madeireiros do mercado. Ou seja, eles atuam como tomadores de preços, uma vez que não têm como influenciar, em suas decisões individuais, o preço de mercado desses produtos. $\mathrm{Na}$ área de estudo, a produção familiar se desenvolve em pequenas áreas e nenhum estabelecimento produz uma quantidade de um dado produto suficiente para abastecer grande parcela do mercado e influenciar variações no preço e o mesmo ocorre com os consumidores;

b) O produto é homogêneo na percepção dos compradores, uma vez que uma unidade de produto comercializada por um produtor é idêntica às quantidades ofertadas pelos demais produtores (são substitutos perfeitos, portanto, não há preferências específicas por um produto de um dado fornecedor). A farinha não é um produto com marca registrada do estabelecimento ou do assentamento em que a mandioca foi cultivada e a farinha fabricada, de modo que o consumidor não a identifica como produto diferenciado;

c) O fluxo de informações sobre preço, custo de mão de obra e de transporte é do conhecimento dos principais agentes do mercado 
(produtores locais e atravessadores) e há mobilidade de fatores (principalmente mão de obra) entre as áreas produtoras e atividades produtivas, em resposta a novas oportunidades no mercado dos produtos;

d) Não existem barreiras fortes para o impedimento da entrada e/ou da saída dos agentes do mercado de produtos agropecuários e florestais a qualquer tempo. Um produtor de milho e feijão podem, sem qualquer impedimento, iniciar a produção de mandioca em sua área e entrar no mercado de farinha.

Em conformidade com estas características, a oferta e demanda dos produtos agropecuários e florestais madeireiros e não madeireiros podem ser especificadas, na forma logarítmica, da seguinte forma (SANTANA, 2003):

$$
\begin{aligned}
& Q_{\text {oit }}=\alpha_{0}+\alpha_{\mathrm{i}} P_{i t}+\phi_{\mathrm{n}} X_{n t}+\left(1-\theta_{i}\right) Q_{\text {oit-1 }}+\varepsilon_{\text {oit }}(1) \\
& Q_{\text {dit }}=\beta_{0}+\beta_{\mathrm{i}} P_{i t}+\varphi_{\mathrm{m}} Z_{m t}+\left(1-\mu_{i}\right) Q_{\text {dit-1 }}+\varepsilon_{\text {dit }}(2)
\end{aligned}
$$

$Q_{(o, d) i t}=$ é o logaritmo da quantidade ofertada e demandada per capita do produto i, no tempo t;

$Q_{(o, d) i t-1}=$ é o logaritmo da quantidade ofertada e demandada per capita do produto $\mathrm{i}$, no tempo $\mathrm{t}-1$;

$P_{i t}=$ é o logaritmo do preço real do produto i, no tempo $\mathrm{t}$;

$X_{n t}=$ é o vetor de variáveis, expressas na forma logarítmica, que influenciam a oferta do produto $n$ (chuva, salário rural e preços dos produtos competitivos com relação ao uso de fatores), no período $t$;

$Z_{m t}=$ é o vetor de variáveis, expressas na forma logarítmica, que influenciam a demanda do produto $m$ (PIB per capita e preços dos produtos substitutos e/ou complementares), no período t;

$\alpha_{i}$ e $\phi_{n}=$ são os parâmetros da equação de oferta a serem estimados $(i=$ $1,2, \ldots, \mathrm{I} ; n=1,2, \ldots, \mathrm{N})$;

$\beta_{i}$ e $\varphi_{m}=$ são os parâmetros ou elasticidades da equação de demanda a serem estimados $(m=1,2, \ldots, \mathrm{M})$;

$\left(1-\theta_{i}\right)=$ é o parâmetro de ajustamento e $\theta_{i}$ é a elasticidade de ajustamento da oferta do produto i a serem estimados;

$\left(1-\mu_{i}\right)=$ é o parâmetro de ajustamento e $\mu_{i}$ é a elasticidade de ajustamento da demanda do produto i a serem estimados;

$\varepsilon_{\text {oit }}$ e $\varepsilon_{\text {dit }}=$ são, respectivamente, os termos de erro das equações de oferta e demanda do produto $\mathrm{i}$, no ano $\mathrm{t}$. 
Na equação 1 , tem-se que a quantidade ofertada $Q_{0}$ do produto i é uma função direta do preço do respectivo produto $P_{i}$. Portanto, espera-se um sinal positivo para o parâmetro $\alpha$, pela Lei da Oferta (SANTANA, 2005). Com relação às variáveis deslocadoras da oferta $X$, espera-se sinal negativo para custo de produção (utilizando o salário rural como proxy), sinal positivo ou negativo para a chuva (proxy da influência climática) e sinais indefinidos para os preços de outras culturas. No caso da demanda (equação 2), especificada pela equação 2, espera-se um sinal negativo entre a quantidade demandada $Q_{d}$ do produto i e o preço do referido produto $P_{i}$, com sinal negativo para o parâmetro $\beta_{i}$, conforme a Lei da Demanda (SANTANA, 2005). Entre as variáveis deslocadoras da demanda estão a renda per capita e o preço de produtos substitutos cuja variação produz impacto no consumo na mesma direção e o preço de produtos complementares, cuja variação produz deslocamento da demanda no sentido contrário.

Os parâmetros das equações de oferta e demanda foram estimados, conforme Santana e Santos (2000), Santana et al. (2011a) e Nogueira et al. (2013), aplicando-se o Método Generalizado dos Momentos (MGM) por incorporar mecanismos para correção de problemas de autocorrelação e heteroscedasticidade dos erros nas equações do sistema. A estatística $J$ de Hansen (1982) foi utilizada para testar a adequação dessas variáveis à especificação do modelo. Um valor próximo de zero indica que as variáveis instrumentais são ortogonais em relação aos erros e as equações são super identificadas, o que atesta como correta a especificação do modelo.

Quanto à identificação do modelo, tem-se que as equações de demanda e oferta foram super identificadas pelas condições de ordem e de posto ou rank (SANTANA, 2003). A estimação do modelo foi realizada pelo MGM, por possibilitar a estimação simultânea do sistema de equações, incluindo as variáveis instrumentais e incorporando o tratamento de autocorrelação dos erros (SANTANA et al., 2011b).

Alguns estudos de mercado de produtos agropecuários, pesqueiros e florestais madeireiros e não madeireiros já foram realizados no estado do Pará e, quando se trata da utilização de modelos econométricos para a estimação das equações de oferta e demanda, destacam-se os seguintes: Barbosa et al. (2007) e Santana et al. (2008) que estudaram o mercado e o APL de peixe no Pará; Santana (2002a) e Santana et al. (2010) que pesquisaram o mercado e comercialização do leite; Santana et al. $(2011 a, b)$ que estudou o mercado de frutas; Santana et al. (2011) e Santana et al. (2014) que analisaram o mercado e comercialização do açaí; Santana (1999) que pesquisou o mercado de carne; Santana e Santos (2000) que estudaram o mercado de feijão caupi; Silva et al. (2010) que investigaram o mercado de óleo de andiroba e copaíba; Santana $(1991$; 1992) que analisou os mercados de castanha - do - brasil no estado do Pará e de carne suína no Brasil. Muitos desses estudos não estimaram os 
coeficientes de elasticidades - preço da demanda e da oferta da economia paraense e nenhum deles se refere à área de pesquisa. Portanto, tais estudos são importantes apenas como elemento de revisão sobre o comportamento do mercado de produtos agropecuários e florestais.

\subsection{Modelo de Projeção do Consumo e da Oferta}

Projetam-se as quantidades ofertadas e demandadas de produtos agropecuários e florestais madeireiros e não madeireiros dos polos comerciais da área de pesquisa. No caso da oferta, a taxa de crescimento da produtividade via utilização de tecnologias apropriadas é considerada 0 principal fator de ampliação da oferta de produtos. Assim como a taxa de crescimento da população e da renda são os fatores mais importantes para explicar as variações da demanda desses produtos. Além dessas variáveis, conforme Santana (2005), pode-se apresentar o modelo de projeção da oferta (equação 3) e da demanda (equação 4), incorporando as forças de mercado, captadas pelas elasticidades - preço, renda e de ajustamento da demanda e as elasticidades-preço, clima, custo e de ajustamento da oferta.

$$
\begin{aligned}
& Q_{i t}=Q_{i 2012}\left(1+\eta_{i} p_{i}+\rho_{i} \text { Chuva }_{i}+\theta_{i} q_{i}\right)^{t}(3) \\
& Q_{i t}=Q_{i 2012}\left(1+h-\phi_{i} p_{i}+\varphi_{i} r_{i+} \mu_{i} q_{i}\right)^{t}(4)
\end{aligned}
$$

$Q_{i t}$ e $Q_{i 2012}=$ é a quantidade total do produto i, ofertada e demandada, respectivamente, nos períodos te 2012, considerado como ano zero;

$\eta, \rho, \theta, p$, chuva e $q=$ elasticidade - preço da oferta, elasticidade chuva, elasticidade - custo e deslocamento da oferta, e taxas de crescimento dos preços, precipitação pluviométrica, salário rural e quantidade do produto ofertado;

$\phi, \varphi, \mu, h, p, r$ e $q=$ elasticidade - preço, renda e deslocamento da demanda, e taxas de crescimento da população, preços, renda e quantidade demandada.

A partir da aplicação desses modelos aos dados obtidos da pesquisa de campo e na projeção dos dados, pode - se identificar os produtos que apresentam equilíbrio de mercado, com demanda igual à oferta e os desequilíbrios por excesso de oferta e/ou por excesso de demanda. Em ambos os casos, mostra-se a tendência de continuidade, ou não, dessas situações de equilíbrio e/ou desequilíbrio atual, bem como a médio prazo. A partir desses resultados, pode-se orientar a tomada de decisão para definir o que e quanto produzir, de acordo com a qualidade e os níveis de agregação de valor aos 
produtos, bem como os canais de distribuição a serem utilizados para atender ao mercado local, regional, nacional e internacional.

\section{RESULTADOS E DISCUSSÃO}

Apresentam-se os resultados da pesquisa de campo sobre o mercado de produtos da pequena produção rural dos polos de Altamira, Itaituba e Santarém. A análise contempla os estabelecimentos que configuram 0 mercado atacadista e varejista dos produtos agrícolas, pecuários, pescado, madeireiros e não madeireiros oriundos da produção local e/ou importado de outros municípios do Pará e de outros estados. Configura-se o mercado institucional dos produtos da agricultura familiar, especialmente de produtores de assentamentos rurais e comunidades tradicionais, que são adquiridos pelos governos municipais e estaduais.

A seguir, apresenta-se a análise do mercado institucional para os produtos da agricultura familiar e de reservas extrativistas, com ênfase na dimensão operacional dos programas e instituições que regulam e dimensionam o mercado na área de estudo. Em seguida, estuda - se o mercado amplo (não institucional) para identificar sua estrutura funcional e os canais de comercialização dos produtos locais e importados, bem como identificar preços e quantidade dos produtos da agricultura familiar com potencial de substituir importações. Por fim, faz-se a projeção da oferta e consumo dos produtos agrícolas, pecuários, pesqueiros, madeireiros e não madeireiros da área de estudo.

\subsection{Mercado Institucional da Produção Familiar}

Nos polos comerciais da área de pesquisa, a Empresa de Assistência Técnica e Extensão Rural (EMATER), o Instituto Nacional de Colonização e Reforma Agrária (INCRA), a Comissão Executiva do Plano da Lavoura Cacaueira (CEPLAC), o Ministério da Pesca e Aquicultura (MPA), o Sindicato de Trabalhadores Rurais de Santarém e de Belterra, o Sindicato de Trabalhadores e Trabalhadoras na Agricultura Familiar e o Conselho Nacional das Populações Extrativistas são os órgãos cadastrados pelo Ministério do Desenvolvimento Agrário (MDA) para emitir a Declaração de Aptidão ao Pronaf (DAP). Este é o instrumento de regulação que viabiliza a participação dos produtores ao mercado institucional.

Atualmente, no polo de Santarém existem mil famílias com potencial para ingressarem no PAA. Destas, apenas 300 famílias estão cadastradas, envolvendo 102 famílias quilombolas, 141 famílias de assentados da reforma agrária e 57 famílias de comunidades tradicionais de várzea e do planalto. A venda dessa produção é isenta de imposto e o pagamento é realizado em até 30 dias. Esse prazo de pagamento é questionado por produtores, sobretudo os 
que realizam operações no mercado spot, ou seja, negociam com o pagamento à vista. A justificativa é que não dispõem de reservas monetárias para esperar o pagamento a prazo.

Nos municípios da pesquisa, as compras iniciaram, mas há problemas na execução do PAA e do PNAE, em função do pequeno excedente e variabilidade de produtos disponibilizados pelos produtores ao mercado, assim como o elevado custo de transação das operações de compra. As compras do PNAE iniciaram nos municípios, a partir do primeiro semestre de 2013 , contudo nenhum deles atingiu os $30 \%$ da cota mínima, em função do elevado custo de transação e a preferência em negociar com empresas para a entrega dos produtos perecíveis que são feitas periodicamente às escolas. Igualmente, nenhum produtor e/ou órgão que o represente conseguiu alcançar o teto estabelecido para as compras pelos programas.

No caso dos produtos da pecuária, o Serviço de Inspeção Federal (SIF) do Ministério da Agricultura, Pecuária e Abastecimento (MAPA) atesta a qualidade sanitária dos produtos de origem animal comercializados no mercado brasileiro e no mercado internacional. O SIE atua na fiscalização de estabelecimentos que comercializam produtos de origem animal dentro do estado e o SIM atua nos estabelecimentos que comercializam produtos no município. No estado do Pará, a Agência de Defesa Agropecuária do Pará (ADEPARÁ) e o MAPA atuam na fiscalização sanitária dos produtos de origem animal.

Os estabelecimentos com certificado SIF conseguem vender o produto para o mercado amplo. Atende ao varejo de supermercado e às demandas de grandes empresas, exportando para outros estados. Os frigoríficos com certificação SIE conseguem comercializar o produto no mercado de todos os polos e com os demais municípios do estado. Por sua vez, os estabelecimentos com aprovação do Serviço de Inspeção Municipal (SIM) só têm permissão para vender para o mercado municipal. No polo de Altamira, os municípios ainda não conseguiram implantar o SIM, mesmo a área estando livre da aftosa com vacinação.

Apenas no polo de Santarém foi encontrado um frigorífico com SIF, que atua no abate de gado e dois com SIE (um no abate gado e outro no beneficiamento de peixe). Outros quatro frigoríficos não apresentam certificação de inspeção sanitária. A empresa avícola também tem SIF e fornece ovos e carne de aves para os demais polos. Nenhum dos laticínios têm certificação.

No polo de Itaituba, um laticínio possui aprovação do Serviço de Inspeção Estadual (SIE) e dois possuem SIM. Já os abatedouros não possuem certificação. Os animais são oriundos de assentamentos e de fazendas privadas. 
No polo de Altamira, o único frigorífico com SIF fechou no final do mês de junho de 2013, justificando a dificuldade para adquirir animais de áreas regularizadas. Há também um frigorífico que possui SIE, no município de Altamira. Contudo, todos os demais abatedouros dos municípios deste polo são clandestinos. Neste caso, não há resfriamento da carne para comercialização. Normalmente, o abate ocorre na madrugada para ser entregue cedo aos açougues.

Com efeito, quase a totalidade do gado em pé é exportado para o estado do Amapá pelo porto de Vitória do Xingu. Esses animais são comprados em áreas de assentamento, inclusive do Bom Jardim, de reservas extrativistas e de propriedades privadas.

Em relação à agroindústria de polpa de frutas, apenas uma apresenta certificação de qualidade para comercializar os produtos no polo de Santarém, porém opera com grande capacidade ociosa acima de $40 \%$. Na verdade, não consegue atender à demanda do mercado local. No polo de Altamira, nenhuma possui certificação.

Os produtos não madeireiros oriundos de Reservas Extrativistas, Flonas Nacionais e Unidades de Conservação são licenciados e fiscalizados pelo IBAMA e também pelo ICMBio. Esses órgãos realizam as atividades de manejo, pesquisa, fiscalização e orientação das comunidades para comercialização dos produtos extrativos (óleos, resinas, cascas, látex, castanhas e sementes) e da produção artesanal (ecobijoux, bolsas, cadernetas, chaveiros, chapéus, tapetes, velas e cremes) realizada pelas comunidades tradicionais. Após a inclusão desses produtos à política de preços mínimos, sem informação, conscientização dos agentes e infraestrutura para viabilizar a comercialização dos produtos, houve uma diminuição significativa no preço dos óleos de copaíba e andiroba e, por consequência, das quantidades ofertadas e comercializadas.

A queda no preço dos óleos de andiroba e copaíba deve-se ao imposto de comercialização e a baixa qualidade do produto. Ao mesmo tempo, os preços da madeira em pé da andiroba e da copaíba aumentaram e, como há facilidade de comercialização dessa madeira em face da legalização das áreas de manejo, as comunidades optam pela venda da árvore, dada a oportunidade de gerar dinheiro imediato, sem incorrer nos custos da extração do óleo. Porém, no horizonte de tempo infinito para o fluxo de extração do óleo, conforme Santana et al. (2008) e Santana et al. (2012), a atividade extrativa do óleo apresenta um retorno superior ao da extração manejada da árvore, cuja sustentabilidade ainda é uma incógnita.

Portanto, há problemas de escala, qualidade e preços competitivos para os três grupos de produtos, bem como problemas de integração e governança das cadeias produtivas. Igualmente, há problemas de regularização fundiária e ambiental (produtores sem DAP), escassez e alto preço da mão de obra rural, 
que são fatores que concorrem para a diminuição da geração de excedente de produção por parte da agricultura familiar e das comunidades tradicionais, no que tange aos produtos mais intensivos em mão de obra como arroz, farinha de mandioca, cacau, pecuária de leite e pesca artesanal. A divulgação dos programas quanto às chamadas públicas para que os produtores e as organizações que os representam participem dos pregões de compra é deficiente, assim como não há conscientização dos produtores sobre os reais propósitos dos programas.

Em nenhum dos mercados - polo atingiu-se a metade do percentual de $30 \%$ de quota mínima para as compras de produtos da agricultura familiar pelo PNAE, envolvendo a aquisição de hortaliças (cheiro verde, couve, alface, pimenta, pepino, cebolinha e chicória), frutas (banana, limão e abobora), polpa de frutas, macaxeira, farinha, geleia de frutas, achocolatado caseiro, colorau e barras de chocolate da Cacauway, cujas compras iniciaram no mês de junho de 2013 e são consideradas inexpressivas.

Para avaliação da influência desse programa na oferta de alimentos, perguntou-se aos entrevistados se conheciam o PAA e/ou PNAE. Em caso afirmativo, buscou-se obter uma informação combinada com análise sobre a sua influência na oferta de alimentos.

Quanto à primeira pergunta, $26,1 \%$ dos entrevistados responderam que conhecem o PAA e/ou PNAE por terem realizado negócio com as instituições que operam o Programa e pelo conhecimento do mercado de produtos agrícolas. Por outro lado, $73,9 \%$ revelaram que não têm conhecimento do PAA e/ou PNAE, não sabem como funciona e, por isso, não emitiram opinião. Quanto à segunda pergunta feita aos que conhecem o PAA e/ou PNAE, obtiveram-se as respostas apresentadas na Tabela 1.

Tabela 1 - $O$ efeito dos programas PAA e PNAE na oferta de alimentos pela agricultura familiar, estado do Pará, 2013

\begin{tabular}{lllll}
\hline Tipo de influência & Altamira & Santarém & Itaituba & Total \\
\hline Positiva & 2 & 10 & 1 & 13,0 \\
Negativa & 2 & 1 & 1 & 3,0 \\
Não sabe & 10 & - & 2 & 13,0 \\
Total & 14 & 11 & 4 & 29,0 \\
\hline
\end{tabular}

Percentagem

$\begin{array}{lllll}\text { Positiva } & 14,3 \% & 90,9 \% & 25,0 \% & 44,8 \%\end{array}$ 


\begin{tabular}{lllll} 
Negativa & $14,3 \%$ & $9,1 \%$ & $25,0 \%$ & $10,3 \%$ \\
Não sabe & $71,4 \%$ & - & $50,0 \%$ & $44,8 \%$ \\
\hline Total & $\mathbf{1 0 0 , 0} \%$ & $\mathbf{1 0 0 , 0} \%$ & $\mathbf{1 0 0 , 0} \%$ & $\mathbf{1 0 0 , 0} \%$ \\
\hline
\end{tabular}

Fonte: Dados da pesquisa.

Dos 29 entrevistados que responderam à pergunta, 44,8\% afirmaram que a influência do PAA na oferta de alimentos foi positiva, uma vez que propiciou a comercialização de produtos como a farinha produzida por agricultores familiares. Outros $10 \%$ informaram que o efeito foi negativo em função da dificuldade de acessar ao Programa, da dificuldade de adquirir o produto, de padronizar em qualidade com embalagens que adéquam ao armazenamento. Além do alto custo de transação da compra fracionada direta dos produtores. O restante, apesar de conhecer o Programa, não sabe avaliar seus efeitos.

Os pontos críticos que estão contidos nos regulamentos e precisam ser equacionados para que as políticas atendam a seus objetivos de base são estes: reduzir pobreza e desigualdade, agregar valor aos produtos; inserir os produtos no mercado amplo; certificar os produtos; organizar e criar capital social; adotar tecnologia; e construir capital humano para empoderar as comunidades de famílias tradicionais e de assentamentos rurais dos programas de reforma agrária. Os objetivos de bases para solucionar esses pontos críticos são estes:

a) Implantar tecnologia que supra a escassez de mão de obra (tecnologia poupadora de mão de obra e/ou que aumente e sua produtividade) e atividades menos intensivas em mão de obra com baixa instrução;

b) Aumentar a qualidade dos produtos por meio da agregação de valor, certificação, embalagem e armazenamento;

c) Organizar e conscientizar os produtores em sindicatos, associação e cooperativas para ampliar a escala individual e coletiva do excedente de produção para atender à demanda do mercado institucional e do varejo de supermercados, mediante a substituição de importação (aumentar a competitividade);

d) Criar infraestrutura para operar a logística de comercialização (transporte, estradas, armazenamento, beneficiamento, embalagem e distribuição) dos produtos da agricultura familiar com vista a atender às demandas do mercado institucional e estabelecer parcerias comerciais com os agentes dos mercados atacadistas e varejistas;

e) Equacionar de forma inteligente e em tempo adequado as irregularidades ambientais, trabalhistas e fundiárias. A superação desses problemas é fundamental para acesso ao crédito e ao mercado amplo; 
f) Disponibilizar assistência técnica para orientar a utilização de tecnologia apropriada, gestão do negócio, acesso aos serviços de legalização fundiária, ambiental e trabalhista, visando habilitá-los a participar dos mercados e criar as condições para empoderar os produtores e as comunidades locais;

g) Superar a escassez de mão de obra para as atividades (açaí, cacau, mandioca, arroz e hortaliças), mediante a combinação de atividades individuais e coletivas, com vistas a otimizar a utilização de tecnologia poupadora de mão de obra e/ou de alta produtividade do trabalho e da terra.

Com efeito, a regulação deve abranger todos os elos das cadeias produtivas (acesso aos insumos, tecnologia, informação e assistência técnica de qualidade, produção, contratos de comercialização, processamento e distribuição). Na unidade de produção, é importante apoiar a construção de ativos coletivos com vistas a formar capital social, criando e fortalecendo os laços de confiança para aglutinar os produtores. E, por conseguinte, esses passem a atuar como organização representativa dos assentados nas negociações com os demais agentes da cadeia e as instituições reguladoras. A partir desse ponto, acessar ao mercado institucional, negociar grandes quantidades de produtos para reduzir o custo de transação das unidades compradoras e desestimular a procurar concorrentes comerciais; inviabilizando a ação de intermediários da comercialização a participar do mercado e reduzindo a margem do produtor. É necessário dotar os assentamentos de unidades de capital coletivo para viabilizar a logística de produção, 0 beneficiamento e a comercialização.

Com isso, pode-se tornar a regulação que atualmente é discricionária em instrumento de maior alcance temporal, dado que pode cumprir a missão de aumentar a produtividade dos sistemas de produção e ampliar os benefícios dos consumidores e produtores. Assim, o esforço cognitivo aplicado na concepção do marco regulador do mercado institucional, mediante operação das ações dos diversos programas de apoio à agricultura familiar e as instituições de interesse pode se coadunar com o problema real vivenciado pelas economias locais e se tornar em instrumentos de política sustentáveis para reduzir as falhas de mercado.

\subsection{Mercado Amplo de Produtos da Agricultura Familiar}

Dos atacadistas que atuam no mercado da área de estudo, a maior parte e de maior escala se encontra no polo comercial de Santarém, seguido dos polos de Altamira e Itaituba (Tabela 2). Com o asfaltamento da BR 163, a construção do porto de Mirititubae a viabilização da hidrovia do Tapajós, os polos de Itaituba e Santarém devem ampliar a escala do mercado atacadista,aproveitando a logística de transporte e comercialização da área de estudo. 
O comércio varejista também está bem representado nos polos de Itaituba e Santarém, com supermercados de médio e pequeno porte, pequenos comércios, feiras livres e mercados municipais em funcionamento. Nas feiras livres e mercados municipais, a maior parte dos produtos comercializados é oriundo da pequena produção, com predominância de hortaliças, frutas regionais, carne, peixe e produtos não madeireiros. A farinha, por sua vez, é um produto genuíno da pequena produção rural e foi encontrada em todos os mercados. Entretanto, antes de chegar ao varejo é beneficiada e entregue em sacas de $30 \mathrm{~kg}$ para a revenda direta aos consumidores nas diferentes formas.

As cooperativas e associações de produtores agrícolas e extrativistas, que representam a parcela da oferta da produção organizada (organizações formadas a partir da base comunitária ou fidelizada para acessar o mercado institucional) estão em atuação nos polos de Altamira e Santarém. Em Itaituba, nenhuma cooperativa quis participar da pesquisa, embora uma cooperativa de laticínio de Rurópolis tenha sido visitada, recusou-se a preencher o questionário. Essas cooperativas, além de venderem para o mercado amplo de produtos, também estão participando do mercado institucional, com a venda de produtos para as prefeituras e a CONAB, que repassam os produtos para os programas PAA e PNAE.

Tabela 2 - Ramo de atividade do estabelecimento entrevistado por polo comercial representativo dos municípios pesquisados, 2013

\begin{tabular}{lllll}
\hline Atividade Principal & Altamira & Santarém & Itaituba & Total \\
\hline Comércio atacadista & 10 & 11 & 6 & 27 \\
Comércio varejista & 5 & 26 & 34 & 65 \\
Cooperativa & 1 & 8 & - & 9 \\
Agroindústria & 6 & 10 & 5 & 21 \\
Intermediário & 7 & 1 & 1 & 9 \\
Total & 29 & 56 & 46 & 131 \\
\hline & Percentual & & & $100 \%$ \\
Comércio atacadista & $37,0 \%$ & $40,7 \%$ & $22,2 \%$ & $100 \%$ \\
Comércio varejista & $7,7 \%$ & $40,0 \%$ & $52,3 \%$ & $100 \%$ \\
Cooperativa & $11,1 \%$ & $88,9 \%$ & - & $100 \%$
\end{tabular}




\begin{tabular}{lllll} 
Intermediário & $77,8 \%$ & $11,1 \%$ & $11,1 \%$ & $100 \%$ \\
\hline Total & $\mathbf{2 2 , 1 \%}$ & $\mathbf{4 2 , 7 \%}$ & $\mathbf{3 5 , 1 \%}$ & $\mathbf{1 0 0 , 0} \%$
\end{tabular}

Fonte: Dados da pesquisa.

Com relação aos produtos da agroindústria (leite pasteurizado, queijos, polpa de frutas, produtos de cacau, arroz beneficiado, farinha de mandioca, carne, pescado beneficiado, madeira beneficiada, óleos vegetais, ecobijoux), com predominância dos produtos da pecuária (carne, queijo e leite), apresentam maior concentração no polo de Santarém, onde os estabelecimentos têm certificado do Serviço de Inspeção Sanitária Federal, Estadual e Municipal (SIF, SIE ou SIM). Nos demais polos, apenas uma agroindústria possui certificação federal. Além disso, operam com grande capacidade ociosa. Os laticínios dos polos de Itaituba e Altamira estão operando com mais de $70 \%$ de capacidade ociosa, os frigoríficos com mais de $60 \%$, uma agroindústria de polpa de frutas com mais de $80 \%$, um laticínio e uma usina de arroz fechados. Ou seja, existe uma base agroindustrial instalada, mas falta oferta de produto em quantidade e qualidade, além de apoio técnico para atendimento à legislação comercial.

Por fim, tem-se a rede de intermediários da comercialização ou de atravessadores, que atuam nos canais de distribuição do produto entre o local de produção e os mercados varejistas, atacadistas e institucional. Esses agentes arcam com o custo de reunir os produtos, adquirindo os pequenos excedentes de produtos como cacau, farinha, frutas e formam um volume que viabiliza o transporte para os mercados com frequência semanal ou mensal. A ação desses agentes contribui para reduzir o custo de transação dos atacadistas e dos órgãos que operam o mercado institucional. Apenas em Altamira houve sucesso em conseguir maior número de intermediários que, apesar da condição generalizada de operação informal desses agentes, não houve imposição de condições para que participassem da pesquisa.

A composição dos produtos in natura e industrializados dos mercados dos polos comerciais de Altamira, Itaituba e Santarém está formada assim: comercializam produtos agrícolas, $61,3 \%$; produtos pecuários, 32,4\%; produtos madeireiros, 8,1\%; produtos não madeireiros, $10,8 \%$; produtos industrializados, $23,4 \%$; peixes, $7,2 \%$; outros produtos diversos, $0,9 \%$. Esses resultados refletem o grau de concentração dos estabelecimentos em função do leque de produtos enquadrados em cada grupo.

Os produtos agrícolas do grupo cereais são distribuídos por atacadistas com grande poder de mercado. Por exemplo: os dois maiores atacadistas de Santarém abastecem mais de $70 \%$ do mercado local e grande parte de outros mercados da área de estudo. Em Itaituba, o maior atacadista apresenta poder 
de monopólio na distribuição desses produtos. O mesmo ocorre com o atacadista de arroz em Uruará. Em relação às frutas, hortaliças e farinha produzidas na área de pesquisa, o mercado varejista é fortemente concorrencial, em função do grande número de vendedores de um produto homogêneo do ponto de vista do consumidor. O mesmo ocorre com os pontos de venda de produtos não madeireiros.

O mercado atacadista de carne é concentrado em um número que varia de um a quatro estabelecimentos que abatem e preparam animais e/ou que processam peixe. Quando se exige qualidade e inspeção sanitária do produto, apenas um frigorífico na área de pesquisa tem SIF e os demais funcionam apenas com o SIE ou com o SIM. O Frigorífico que tem SIF desfruta de uma reserva de mercado para negociar em escala maior e para atender diversos mercados do varejo, instituições e grandes empresas. Os mercados varejistas da carne (açougues) e do peixe (boxes para venda de peixe) operam em estrutura próxima da concorrência pura. Por outro lado, o varejo de supermercado, dada a maior exigência em qualidade do produto, exerce um elevado poder de mercado pelas condições diferenciadas de compra e venda dos produtos.

Essa diferenciação de mercados atacadistas e varejistas torna mais complexa a identificação e a operacionalização da logística dos canais de comercialização dos produtos, em função das exigências em qualidade, embalagem, quantidade, regularidade na oferta e nos contratos.

\subsection{Taxas de Crescimento, Projeção do Consumo e da Oferta}

Analisou-se a evolução das taxas geométricas de crescimento das variáveis preço e quantidade para cada produto e as variáveis renda, salário rural e chuvas para a área de estudo no período de 2000 a 2011. Em seguida, determinou-se os níveis de consumo e da oferta per capita para cada produto, relativo ao ano de 2012, e projetou-se tais resultados para o ano 2020.

\subsubsection{Taxas de Crescimento}

No período analisado, conforme Santana (2013), a população e o PIB per capita da população da área de pesquisa apresentaram taxas de crescimento médio anual de 1,62\% e 3,39\%, respectivamente. Esses fatores produzem deslocamentos positivos na demanda dos diversos produtos considerados normais ou superiores. $O$ crescimento da população corresponde ao comportamento inercial da demanda, independente dos efeitos dos demais fatores. O poder de compra, por sua vez, incrementa o consumo e contribui para a ampliação do mercado. A taxa de crescimento anual da renda foi de 
$3,39 \%$, do salário rural foi de $0,287 \%$ e do preço e da quantidade variou de acordo com o produto (SANTANA, 2013).

Em relação à evolução dos preços no período analisado, um conjunto significativo de produtos apresentou queda nos preços de mercado como abacaxi, arroz, banana, leite e ovos de galinha, o que contribuiu para incrementar as quantidades demandadas. Por outro lado, os produtos feijão, farinha e carne de boi apresentaram crescimento dos preços de mercado, o que tende a reduzir as quantidades consumidas. No caso da oferta, a influência dessa variável tem efeito inverso ao da demanda.

No que tange às taxas médias de crescimento das quantidades dos produtos transacionados no mercado local, têm-se que algumas exibiram variações positivas e outras negativas. Nesse caso, os efeitos do ajustamento temporal sobre a demanda e a oferta ocorrem na mesma direção, resultando na diminuição ou expansão do mercado.

A taxa de crescimento da precipitação pluviométrica média foi de $0,349 \%$ ao ano. Esse incremento das chuvas pode exercer efeito positivo para algumas lavouras e negativo para outras, conforme foi analisado na seção anterior. Alguns produtos da agricultura familiar como o arroz, a banana, a melancia e a castanha-do-pará, que não dispõem de local para fazer o armazenamento e/ou beneficiamento industrial do produto, sujeitam-se aos problemas de transporte, agravados pelas condições de trafegabilidade das estradas.

Em relação aos alguns produtos como limão, melancia, açaí, mel e madeira, o salário rural evoluiu no período a taxa média anual de $0,287 \%$, representando forte impacto nos custos de produção e influenciando negativamente a oferta.

\subsubsection{Projeção do Consumo e da Oferta}

As dotações de demanda e oferta relativas ao ano de 2012 foram determinadas com base nas informações geradas na pesquisa de campo, dados da pesquisa de orçamento familiar (POF) e a disponibilidade da produção da área pesquisada. Os valores foram ajustados em termos de consumo e oferta per capita. No caso de produtos como milho e cacau foram $_{2}$ considerados o consumo animal e industrial local, assim como as perdas na comercialização. Em relação à carne, trabalhou-se com o equivalente carcaça para a oferta de animais para abate, adotando-se o percentual de $16 \%$ para a taxa de abate, $48 \%$ para o rendimento de carcaça e peso de carcaça de 13,5 arrobas. O arroz foi considerado na forma polido, após considerar $20 \%$ das perdas na colheita, transporte e armazenamento do produto. No caso da 
mandioca, adotou-se o coeficiente de transformação em farinha de $25 \%$, após considerado os percentuais de $10 \%$ de perda na colheita e na comercialização.

Aplicando-se esses resultados, juntamente como os coeficientes de elasticidade de cada produto, pode-se projetar a demanda e a oferta para os períodos subsequentes, admitindo-se que as condições de mercado estabelecidas permanecem constantes ao longo do tempo. Com base nessas informações, gerou-se as estimativas para a demanda e a oferta per capita de 2012 (Tabela 3).

Tabela 3 - Valores estimados da demanda e oferta para $2012(\mathrm{em} \mathrm{kg})$, taxas de crescimento incorporando as forças do mercado e valores projetados da demanda e oferta para 2020 (em kg e ovos em dz), estado do Pará, 2013

\begin{tabular}{lrrrrrr}
\hline Produto & D2012 & $\mathbf{0 2 0 1 2}$ & $\begin{array}{c}\text { TC } \\
\text { demanda }\end{array}$ & $\begin{array}{c}\text { TC } \\
\text { oferta }\end{array}$ & $\begin{array}{r}\text { Demanda } \\
\mathbf{2 0}\end{array}$ & $\begin{array}{r}\text { Oferta } \\
\mathbf{2 0}\end{array}$ \\
\hline Abacaxi & 3,066 & 4,717 & 0,1032 & 0,0407 & 6,729 & 6,489 \\
Arroz & 34,329 & 92,781 & 0,0698 & $-0,0349$ & 58,885 & 69,801 \\
Banana & 5,277 & 50,983 & 0,0422 & 0,0144 & 7,343 & 57,144 \\
Cacau & 5,369 & 53,693 & 0,0985 & 0,0210 & 11,382 & 63,389 \\
Café & 2,388 & 9,215 & $-0,0618$ & $-0,0836$ & 1,433 & 4,582 \\
Coco-da - & & & & & & \\
baía & 2,294 & 11,878 & $-0,0656$ & $-0,0733$ & 1,333 & 6,463 \\
Feijão & 11,811 & 10,685 & 0,0290 & 0,0073 & 14,849 & 11,328 \\
Farinha de & & & & & & \\
mandioca & 30,294 & 93,308 & 0,0648 & 0,0447 & 50,079 & 132,434 \\
Guaraná & 0,015 & 0,025 & $-0,0130$ & $-0,0170$ & 0,014 & 0,021 \\
Laranja & 1,175 & 16,071 & $-0,0332$ & $-0,0481$ & 0,897 & 10,832 \\
Limão & 0,817 & 2,289 & 0,0460 & 0,0021 & 1,170 & 2,328 \\
Mamão & 0,862 & 1,418 & $-0,0235$ & 0,0486 & 0,712 & 2,072 \\
Maracujá & 0,356 & 0,237 & 0,1141 & 0,0604 & 0,845 & 0,379 \\
Melancia & 8,561 & 27,856 & 0,2103 & 0,2189 & 39,421 & 135,702
\end{tabular}


Milho

$$
80,760 \quad 72,592
$$

0,0341

0,0363

105,609

96,540

Pimenta - do

- reino

$$
0,161
$$

4,792

$-0,0602-0,0259$

0,098

3,885

Tomate

$3,688 \quad 4,244$

$0,0705 \quad 0,0014$

6,361

4,292

Madeira em

tora

$$
0,051 \quad 1,016
$$

$0,0145 \quad 0,0013$

$0,057 \quad 1,027$

Castanha -

do - pará

$$
0,145 \quad 0,684
$$

$0,0633 \quad 0,0816$

0,237

1,281

Óleos

vegetais

0,015

0,036

$0,0707 \quad 0,0361$

0,026

0,047

Açaí fruto

0,818

0,721

$0,0470 \quad 0,0243$

1,181

0,874

Carne de boi

$21,922 \quad 55,060$

$0,1005 \quad 0,0631$

47,148

89,812

Leite de vaca

$40,145 \quad 19,658$

$0,0403 \quad 0,0174$

55,071

22,561

Mel de

abelha

$0,527 \quad 16,073$

0,1942

0,1015

2,181

34,823

Ovo de

galinha

$9,023 \quad 3,037$

$0,0385-0,0186$

$12,211 \quad 2,612$

Ovo de

codorna

$0,161 \quad 0,143$

$0,0245 \quad 0,0049$

0,195

0,149

Galinha

caipira

$$
0,834 \quad 0,510
$$

0,0162

0,948

0,510

Frango de

granja

$17,285 \quad 6,789$

0,0162

19,652

6,789

Carne de

ovino

$$
0,045 \quad 0,021
$$

0,0162

0,051

0,021

Peixe

$13,961 \quad 17,124$

0,0162

15,873

17,124

Fonte: Dados da pesquisa. Oferta de farinha é o resultado da transformação de $70 \%$ da produção de raiz com rendimento de $25 \%$ ( $1 \mathrm{t}$ de raiz $=250 \mathrm{~kg}$ de farinha).

O balanço entre oferta e demanda é dado pela relação de igualdade entre as duas. Se a oferta for maior do que a demanda, tem-se um excesso de 
oferta, que se permanecer durante mais de uma safra pode determinar a queda dos preços do produto para que se atinja o equilíbrio do mercado, caso não se tenha a opção de industrializar e/ou exportar o excedente. Por outro lado, se a demanda for superior à oferta, tem-se um excesso de demanda, que se for permanente força eleva os preços para um patamar mais alto, caso não haja desova de estoques e/ou importação de produtos para equilibrar o mercado.

Pelos resultados da Tabela 3, tem-se excesso de oferta para diversos produtos em 2012. São os casos do arroz, farinha, carne de boi, peixe, cacau, madeira, castanha-do-pará e a maioria das frutas. Todos esses produtos estão sendo exportados para municípios próximos da área de pesquisa e para outros estados. Por outro lado, uma cesta de produtos importantes apresentou excesso de demanda em 2012. Entre eles estão feijão, milho, leite, ovo de galinha e frango de granja, cujo déficit é abastecido com a importação de produtos de outros municípios e estados.

Em 2020, a magnitude do desequilíbrio aumentará para quase todos os produtos, exceto para abacaxi, arroz e tomate que reverteram o desequilíbrio e produziram excesso de demanda significativo (Tabela 3 e Figura 1). Como exemplo, da projeção da demanda e oferta dos produtos, pode-se tomar o caso da demanda e oferta de arroz para exemplificar:

$$
\begin{aligned}
& Q_{d} 2020=34,329 \times(1+0,069776)^{8}=58,885(5) \\
& Q_{0} 2020=92,781 \times[1+(-0,03495)]^{8}=69,800(6)
\end{aligned}
$$

Portanto, tem-se um excesso de oferta sobre a demanda de 10,92 kg/hab./ano. Essa situação é grave, pois, em 2012, o mercado apresentou um excesso de oferta de 47,536 kg/hab./ano. Logo, a redução do excesso de oferta foi de $81,31 \%$, dado que a oferta declinou mais rápido do que a evolução do consumo. Isso indica a perda de competitividade dessa lavoura no mercado local, o que pode significar em importações de arroz em longo prazo, caso as forças definidoras da oferta e demanda não mudem. Atualmente, produção ofertada pela agricultura familiar diminuiu em função da escassez, do alto preço da mão de obra e da ausência de infraestrutura de comercialização. A produção comercial, por sua vez, continua em queda porque o cultivo do arroz é realizado em rotação com o cultivo da soja, porém muitos produtores utilizam o milho ou outra lavoura como substituto do arroz nesse processo. Por outro lado, em função do aumento do poder aquisitivo da população local, a demanda do arroz continuou aumentando no período analisado.

Alguns produtos como leite, ovo de galinha, frango de granja, arroz e feijão tendem a continuar com um consumo abaixo da média brasileira e/ou do estado do Pará, mesmo apresentando taxas de evolução significativa no 
consumo. A carne e o peixe, por sua vez, o consumo tende a ultrapassar e se manter acima da média do consumo brasileiro. O peixe, por sua vez, não apresenta reação na oferta, em função da redução dos estoques e da venda de grande parte do produto da pesca artesanal para outros mercados.

Por fim, a partir dos resultados apresentados na Tabela 3 e ilustrados na Figura 1 visualizam-se três trajetórias evolutivas claramente definidas e que orientam para ações de planejamento da produção e comercialização na área da pesquisa. A primeira trajetória diz respeito ao incremento do excesso de oferta sobre a demanda ao longo do tempo como são os casos da melancia, farinha, carne de boi, cacau, castanha - do - pará, madeira e óleos, o que orienta para a necessidade de agregação de valor e busca de mercados importadores para o escoamento do excedente, assegurando o equilíbrio do mercado. Caso esse padrão de comportamento seja confirmado e não haja mudança no planejamento da produção e comercialização, o excesso de produto pode causar grande redução nos preços e produzir forte instabilidade na renda dos produtores e no orçamento dos consumidores, em função das características de inelasticidade - preço da demanda e da oferta desses produtos:

Figura 1 - Balanço entre oferta e demanda per capita de produtos nos polos de Altamira, Santarém e Itaituba, estado do Pará, 2013 (em kg)

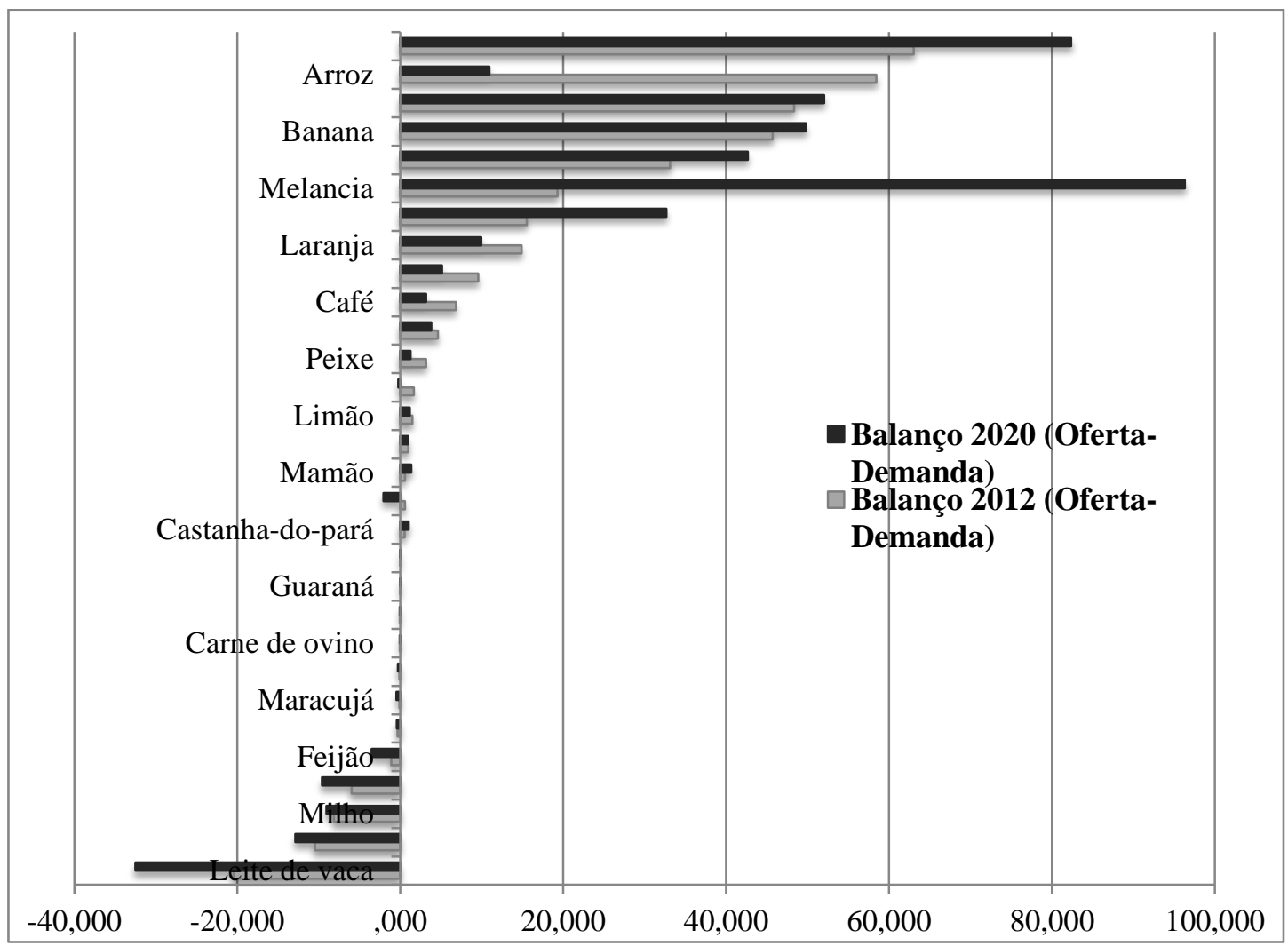

Fonte: Dados da pesquisa. 
A segunda trajetória foi definida pelos produtos laranja, café e peixe, que apresentaram diminuição do excesso de oferta sobre a demanda no período analisado. O comportamento de mercado desses produtos revela que a produção da área pesquisada está perdendo competitividade para os produtos importados, o que tende a gerar impactos negativos no emprego, renda e qualidade de vida da população local. Sendo assim, torna - se urgente a reversão dessa tendência com vistas a recuperar a competitividade da produção familiar e evitar a diminuição de sua parcela de mercado.

A terceira trajetória é representada, principalmente, pelo leite, frango de granja, milho, ovo de galinha, feijão e arroz, que apresentaram déficit de oferta em 2012 e tendência de ampliação da magnitude desse déficit ao longo do tempo. Esses produtos são típicos da agricultura familiar e apresentam ampla repercussão nas condições econômicas, sociais e ambientais da área de estudo, em que problemas de infraestrutura, tecnologia e organização da produção estão configurando esse quadro de forte entropia para a economia local.

Essas duas últimas trajetórias de evolução contemplam 19 produtos ou $63,33 \%$ do total de produtos analisados. A tendência revelada para o futuro pode culminar na redução do mercado de alguns desses produtos a subsistência das comunidades rurais e, no caso de outros produtos, podem ocorrer a total eliminação da oferta pelas razões apresentadas na seção sobre as exigências do mercado consumidor.

Dessa forma, os polos comerciais da área pesquisada tendem a continuar com a especialização da produção dos 11 produtos que apresentaram excesso de oferta, sendo que a especialização pode se concentrar apenas nos produtos das cadeias com amplo mercado, que são a pecuária de corte, extração de madeira, cacau e farinha de mandioca. Ou seja, dessa cesta de produtos, apenas cacau e farinha são produtos genuínos da agricultura familiar da área pesquisada. Como a farinha e o cacau são intensivos em mão de obra, corre-se o risco da pecuária e da extração de produtos madeireiros e não madeireiros dominarem a configuração dos projetos de assentamentos da reforma agrária. O caso do cacau, cuja produção está sendo viabilizada pelas relações de parcerias, por falta de mão de obra, teve a situação agravada pela intervenção do Ministério do Trabalho com o intento de aplicar a Consolidação das Leis do Trabalho (CLT) nas relações trabalhistas em curso, consideradas irregulares. Os seja, a tendência aponta para uma especialização polarizada em duas commodities, caso o portfólio de políticas públicas federais, estaduais e municipais não convirja para realizar as correções de rumo da trajetória de desenvolvimento local e sustentável da área pesquisada. 


\section{CONSIDERAÇÕES FINAIS}

Problemas estruturais recorrentes continuam limitando 0 desenvolvimento da produção familiar. Nas condições atuais dos programas de transferência de renda, foram agravados diante do risco da comercialização produzido pelas condições precárias das estradas, do transporte, da escassez de mão de obra, do alto preço da diária, da inexistência de centrais de armazenamento nos polos comerciais de Altamira, Itaituba e Santarém. Além disso, ação da rede de atravessadores.

O desafio é a utilização de tecnologias poupadoras de mão de obra não qualificada e terra diante das condições de escassez de trabalhadores nas unidades rurais e a exigência de escala mínima para viabilizar os sistemas de produção. Assim, é necessário planejar a combinação de sistemas diversificados com monocultivo e manejo florestal, na perspectiva de atender ao autoconsumo e ampliar os excedentes comercializáveis, sem destruir os recursos naturais.

Para atenuar tais questões, devem-se atender aos requisitos do mercado institucional e as regras dos contratos de integração para garantir oferta regular na quantidade, qualidade exigida e preços competitivos. Organizar os produtores para que a produção alcance uma escala competitiva e viabilize a agregação de valor aos produtos. Solucionar os problemas de insuficiência e deficiência de assistência técnica pública para planejar a produção, combinando áreas de monoculturas com sistemas diversificados para otimizar a utilização de tecnologias químicas e mecânicas, difundir e implementar tecnologias apropriadas em atividades individuais e coletivas de acordo com as condições edafoclimáticas e a capacidade de gestão dos agentes.

O excedente gerado na pequena produção não integrada é transformado em mercadoria pelos intermediários. A venda direta individual e/ou organizada não está conseguindo atender nem mesmo ao mercado institucional, uma vez que o excedente de produção além de pequeno é alcançado por uma pequena parcela dos agricultores.

Como os produtos apresentam, em geral, oferta e demanda inelásticas a preço, a estabilidade da renda dos produtores depende diretamente do mercado institucional e, sobretudo, da qualidade e da agregação de valor aos produtos. Portanto, as políticas analisadas no trabalho (PRONAF, PAA e PNAE) devem ser ajustadas e ampliadas para fazer operar o efeito multiplicador de produção, emprego e renda na economia local. No lado da demanda, o principal fator indutor do aumento do consumo é a renda per capita. Portanto, as políticas de transferência de renda estão exercendo um papel fundamental para o mercado de produtos da agricultura familiar e não familiar na área da pesquisa. Do lado da oferta, as condições climáticas, captadas pelas variações das precipitações pluviométricas causaram grande 
influência negativa na oferta da maioria dos produtos. Este ponto é fundamental, pois tende a se agravar com o lago formado pela UHE Belo Monte, o que exige um zoneamento climático orientado para as atividades agropecuárias, pesqueiras e florestais, tendo em vista a diminuição do risco climático.

No sistema de produção atual, arroz, farinha, carne de boi, mel de abelha, pimenta - do - reino, café, peixe, cacau, madeira, castanha-do-pará e a maioria das frutas tendem a continuar apresentando oferta maior do que a demanda, enquanto que feijão, milho, leite in natura, galinha caipira, ovo de galinha, açaí fruto, carne de ovino e ovo de codorna apresentam demanda superior à oferta. No caso dos produtos com superávit de oferta, deve-se pensar na expansão do mercado a partir da agregação de valor, melhoria na qualidade e certificação com a marca agricultura familiar de baixo carbono. No caso dos produtos em que há déficit de oferta, o mercado está sendo abastecido com a produção de municípios do entorno da área de pesquisa, na maioria dos casos, e com importações dos produtos com maior valor agregado, o caminho é iniciar o fortalecimento da produção, orientando-se, inicialmente, para o mercado institucional, mas sem perder o foco do aumento da escala, melhoria da qualidade e agregação de valor para o mercado amplo local e nacional.

Por fim, a combinação da escala de produção com a utilização de tecnologia de altos insumos, exige um zoneamento agroecológico, edafoclimático e socioeconômico das áreas dos assentamentos para a definição dos sistemas de produção e escolher a combinação entre os sistemas em monocultivo e os sistemas diversificados de produção, tanto dentro do estabelecimento, quanto em área coletiva. Nesse ponto, a organização de base é uma condição necessária e de suficiência para a estruturação das cadeias produtivas. Ou seja, a organização focada apenas na fidelidade aos programas e políticas públicas não produzem os enraizamentos necessários ao processo de desenvolvimento local e sustentável.

\section{REFERÊNCIAS}

BARBOSA, J. A. et al. Características comportamentais do consumidor de peixe no mercado de Belém. Boletim Técnico-Científico do CEPNOR, v.7, p.115 - 133, 2007.

COSTA, N. L.; SANTANA, A. C.; BASTOS, A. P. V. Desenvolvimento tecnológico, produtividade do trabalho e expansão da cadeia produtiva da soja na Amazônia Legal. In: SANTANA, A. C. Mercado, cadeia produtiva e desenvolvimento rural na Amazônia. Belém: UFRA, 2014. p.81-111.

HANSEN, L.P. Large Sample Properties of Generalized Method of Moments Estimator. Econometrica, v. 50, № 4, p. 1029-1054, 1982. 
IBGE. Instituto Brasileiro de Geografia e Estatística. Censo Agropecuário Pará. Rio de Janeiro: IBGE, 2008..

LEI 11326, de 24 de julho de 2006. Disponível em: http://presrepublica.jusbrasil.com.br/legislacao/95601/lei-11326-06. Acesso em: 02 de junho de 2013.

NOGUEIRA, A. K. M.; SANTANA, A. C.; GARCIA, W. S. A dinâmica do mercado de açaí fruto no estado do Pará: de 1994 a 2009. Revista Ceres, v.60, p.324 - 331, 2013.

OLIVEIRA, C. M.; SANTANA, A. C.; HOMMA, A. K. O. Os custos de produção e a rentabilidade da soja nos municípios de Santarém e Belterra, estado do Pará. Acta Amazônica, v.43, p.23 - 32, 2013.

SANTANA, A. C. Análise da comercialização e dos custos na cadeia produtiva de leite na Amazônia. In: SANTANA, A. C.; AMIN, M. M. Cadeias produtivas e oportunidades de negócio na Amazônia. Belém: Unama, 2002a. p. 157-178.

Cadeias agroindustriais e desenvolvimento econômico na Amazônia: análise de equilíbrio geral. In: HOMMA, A. K. O. (Org.) Amazônia: maio ambiente e desenvolvimento agrícola. Brasília - DF : Embrapa, 1998, p. 221-264.

Mercado de produtos agropecuários e florestais dos polos de Altamira, Itaituba e Santarém, estado do Pará. Belém: UFRA/FUNPEA/IPAM, 2013. (Relatório de Pesquisa).

Cadeias produtivas setoriais e o curso do desenvolvimento local na Amazônia. In: Agricultura Tropical: quatro décadas de inovações tecnológicas, institucionais e políticas. Brasília : Embrapa, 2008, v.2, p. $275-291$

Custo social da depredação da castanha - do brasil no Pará. Economia Rural, v.3, p.7 - 10, 1991.

Elementos de economia, agronegócio e desenvolvimento local. Belém, PA: UFRA, 2005. p.197.

Estrutura da oferta de carne suína sob condições de risco no Brasil. Revista de Economia e Sociologia Rural, v.30, p.21 - 39, 1992.

SANTANA, A.C.; SANTANA, Ádamo. L.; SANTANA, Ádina L.; SANTOS, M. A. S.; OLIVEIRA, C. M. Análise discriminante múltipla do mercado varejista de açaí em Belém do Pará. Revista Brasileira de Fruticultura, São Paulo, v.36, p.532 - 541, 2014.

SANTANA, A. C.; CARVALHO, D. F.; MENDES, F. A. T.; BOTELHO, M. N.; KITABAYASHI, R. T. Identificação e caracterização de arranjos produtivos 
locais nos estados do Pará e Amapá, no período de 2000 a 2005: orientações para políticas de desenvolvimento local. Belém: Unama, 2010.

SANTANA, A. C.; SANTANA, A. L.; SANTOS, M. A. S. Influência do desmatamento no mercado de madeira em tora da região Mamuru Arapiuns, Sudoeste do Pará. Revista de Ciências Agrárias, v.54, p.44 - 53, 2011a.

SANTANA, A. C.; CAMPOS, P. S. S.; RAMOS, T. J. N.; GALATE, R. S.; MOTA, A. V. O mercado de frutas no estado do Pará: 1985 a 2005. Revista de Estudos Sociais, v.13, p.174 - 185, 2011b.

SANTANA, A. C. et al. 0 valor econômico da extração manejada de madeira no Baixo Amazonas, Estado do Pará. Revista Árvore, v.36, p.527 536, 2012.

SANTANA, A. C. Fatores sustentáveis do desenvolvimento das cadeias produtivas de base agrária na Amazônia. Ver - a - Ciência, v.1, p.18 - 23, 2012.

SANTANA, A. C. Métodos quantitativos em economia: elementos e aplicações. Belém: UFRA, 2003. p.485.

SANTANA, A. C. Mudanças recentes nas relações de demanda de carne no Brasil. Revista de Economia e Sociologia Rural, v.37, p.51 - 76, 1999.

SANTANA, A. C.; SANTOS, M. A. S. O mercado de caupi no Estado do Pará: aplicação do método dos momentos generalizados. Revista de Ciências Agrárias, v.43, p.47 - 58, 2000.

SANTANA, A. L.; SANTANA, A. C.; FREITAS, D. R. Estimação da demanda de leite no mercado varejista de Belém, estado do Pará. Amazônia: Ciência \& Desenvolvimento, v.6, p.103-116, 2010.

SILVA, E. N.; SANTANA, A. C.; SILVA, I. M.; OLIVEIRA, C. M. Aspectos socioeconômicos da produção extrativista de óleos de andiroba e de copaíba na floresta nacional do Tapajós, Estado do Pará. Revista de Ciências Agrárias, v.1, p.12 - 23, 2010.

Submetido em: 10/05/15

Aceito em: 20/09/15 